\title{
Atrial fibrillation and coronary artery bypass grafting: The question is no longer why, but why not?
}

\author{
J. Scott Rankin, MD, Harold G. Roberts, MD, and Vinay Badhwar, MD
}

\author{
From the Department of Cardiovascular and Thoracic Surgery, West Virginia University, Morgantown, WVa. \\ Disclosures: J.S.R. and H.G.R. are consultants for Atricure. V.B. is a consultant for Atricure and Medtronic. \\ Received for publication Feb 4, 2018; accepted for publication Feb 11, 2018; available ahead of print March 7 , \\ 2018 . \\ Address for reprints: Vinay Badhwar, MD, Department of Cardiovascular and Thoracic Surgery, West Virginia \\ University, 1 Medical Center Dr, Morgantown, WV 26506-8059 (E-mail: vinay.badhwar@wvumedicine.org). \\ J Thorac Cardiovasc Surg 2018;155:2368 \\ $0022-5223 / \$ 36.00$ \\ Copyright (c) 2018 by The American Association for Thoracic Surgery \\ https://doi.org/10.1016/j.jtcvs.2018.02.021
}

In their study in the current issue of the Journal, Malaisrie and colleagues ${ }^{1}$ examined 24,059 patients undergoing isolated coronary artery bypass grafting (CABG) with preoperative atrial fibrillation (AF). By linking clinical registry data with Medicare records and comparing these patients with patients undergoing $\mathrm{CABG}$ without $\mathrm{AF}$, Malaisrie and colleagues ${ }^{1}$ determined that untreated AF was independently associated with a higher 30-day mortality and significantly reduced 5-year survival.

This elegant analysis by Malaisrie and colleagues ${ }^{1}$ clearly establishes that preoperative AF at the time of CABG is not innocuous. In an examination of contemporary patients presenting with $\mathrm{AF}$ at the time of all cardiac operations, patients undergoing $\mathrm{CABG}$ currently receive the lowest rate of surgical ablation (SA) at only $33 \%$, whereas across all operative categories, SA is associated with reductions in 30-day mortality and stroke. ${ }^{2}$ The management of AF at the time of CABG with SA is thus a clear area for potential quality improvement.

In a recent meta-analysis, the impact of preoperative $\mathrm{AF}$ on early and late outcomes after CABG was associated with an increased risk of early and late mortality (odds ratio, 1.64; and hazard ratio, 1.74 , respectively), with morbidities such as stroke, renal failure, and respiratory complications being higher. ${ }^{3}$ The results of the current study of Malaisrie and colleagues ${ }^{1}$ correlate well with these data to establish firmly the concept that $\mathrm{AF}$ at the time of $\mathrm{CABG}$ is far from benign and that SA may affect survival. ${ }^{4}$

Mounting data regarding the negative impact of AF and the relative safety of adding SA to cardiac operations ${ }^{1,2}$ support the recent expert consensus and clinical practice guidelines that consider SA at the time of CABG a class I recommendation. ${ }^{5,6}$ But can we modify the adverse consequences of $\mathrm{AF}$ in $\mathrm{CABG}$ patients by performing SA? In a recent similar analysis of Medicare beneficiaries with AF undergoing $\mathrm{CABG}$, patients receiving SA experienced a $42 \%$ risk-adjusted mortality reduction at 1 year. not?

\section{References} 2358-67.e1. 1524-33.e2. 2018; 155:1534-5.

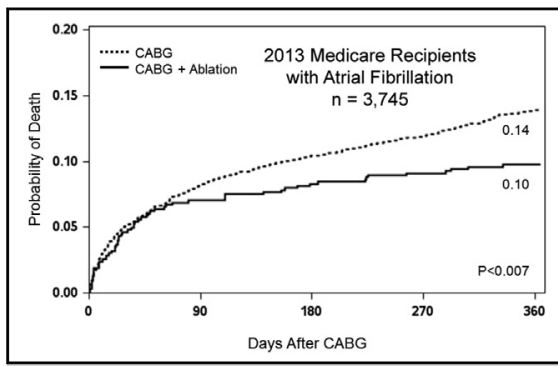

Surgical ablation of atrial fibrillation at the time of CABG may reduce 1-year mortality.

\section{Central Message}

Atrial fibrillation at the time of CABG is associated with increased 30-day mortality and reduced 5-year survival. Surgical ablation should be considered to improve quality and reduce mortality.

See Article page 2358.

Malaisrie and colleagues ${ }^{1}$ thus definitively establish the adverse early and late outcomes associated with AF in patients undergoing $\mathrm{CABG}$. Given the intensifying data in support of SA for AF at the time of $\mathrm{CABG}$, the real management question is not why should we perform SA, but why

1. Malaisrie SC, McCarthy PM, Kruse J, Matsouaka R, Andrei AC, Grau Sepulveda MV, et al. Burden of preoperative atrial fibrillation in patients undergoing coronary artery bypass grafting. J Thorac Cardiovasc Surg. 2018;155

2. Badhwar V, Rankin JS, Ad N, Grau-Sepulveda M, Damiano RJ, Gillinov AM et al. Surgical ablation of atrial fibrillation in the United States: trends and propensity matched outcomes. Ann Thorac Surg. 2017;104:493-500.

3. Saxena A, Virk SA, Bowman S, Chan L, Jeremy R, Bannon PG. Preoperative atrial fibrillation portends poor outcomes after coronary bypass graft surgery: a systematic review and meta-analysis. J Thorac Cardiovasc Surg. 2018;155:

4. Cook CC, Rankin JS, Badhwar V. The importance of atrial fibrillation at the time of coronary artery bypass grafting: join in the chorus. J Thorac Cardiovasc Surg

5. Ad N, Damiano RJ Jr, Badhwar V, Calkins H, La Meir M, Nitta T, et al. Expert consensus guidelines: examining surgical ablation for atrial fibrillation. J Thorac Cardiovasc Surg. 2017;153:1330-54.e1.

6. Badhwar V, Rankin JS, Damiano RJ, Gillinov AM, Bakaeen FG, Edgerton JR, et al. The Society of Thoracic Surgeons 2017 clinical practice guidelines for the surgical treatment of atrial fibrillation. Ann Thorac Surg. 2017;103:329-41.

7. Rankin JS, Lerner DJ, Braid-Forbes MJ, Ferguson MA, Badhwar V. One-year mortality and costs following surgical ablation for atrial fibrillation concomitant to coronary artery bypass grafting. Eur J Cardiothorac Surg. 2017;52:471-7. 